\title{
Towards an integrated model of defense in gynecological cancer. Psychoneuroimmunological and psychological factors, between risk and protection in cancer: A review
}

Chiara Cosentino* and Carlo A. Pruneti

Department of Clinical and Experimental Medicine, University of Parma, Italy

\begin{abstract}
Current cancer conceptualization and management focuses it as a chronic disease that could be directly modulated by psychosocial stressors. An individual is considered a cancer survivor from the time of diagnosis and from the balance of his or her life, including health, mental states, identity, sexuality and financial standings. Moving within the theoretical frames of Psycho- oncology and Psychoneuroimmunology (PNI), this review aims to analyze, in cancer population and in the specific subsample of ovarian cancer, literature regarding PNI pathways as cancer exacerbating factors, PNI pathways promoting cancer survivorship, adaptive psychological variables linked to Quality of Life and specific areas of psychological pain. Scientific books and full-text articles published in English between 20032013were collected. Evidences were collected of the key role of the stress activation main secretions on tumorigenesis and tumor progression, highlighting the role of life events coping. Evidences of the protective role of Parasympathetic Nervous System activation, expressed through the Heart Rate Variability in cancer survivorship and quality of life were also collected. Were detected the main psychological issues in cancer and specific critical psychological sufferance for Ovarian Cancer (sexual impairments, body image alterations). Was also identified the protective central role of Social Support in cancer adjustment. This literature systematic review seems to give the possibility to hypothesize a new model, here called "Integrated Model of Defense" which, integrating psychological and physiological factors, could suggest a protective mechanism in time and quality of survivorship in cancer and, more specifically, in Gynecological Cancer.
\end{abstract}

\section{Introduction}

Current cancer conceptualization and management focuses on cancer issue as a chronic disease that could be directly modulated by psychosocial stressors [1]. Cancer survivorship has been defined in the National Comprehensive Cancer Network 2013 Guidelines: “an individual is considered a cancer survivor from the time of diagnosis from the balance of his or her life. Family members, friends and caregivers are also impacted. The vast and persistent impact could be on health, physical and mental states, health behaviors, professional and personal identity, sexuality and financial standings".

This led to the evidence of needing an holistic approach to cancer and cancer survivorship, as an urgent an current topic, as testified by the «Patient-centered cancer treatment planning: improving the quality of oncology care: Workshop summary» where the attention is addressed to the importance of comprehensive cancer care (Institute of Medicine's, 2011).

Strictly linked to this holistic vision of cancer care is the area of Psychoneuroimmunology (PNI), that is a catalyst in biobehavioral research in cancer, highlighting the neuroimmunological paths through which psychosocial factors as stress, pain, and loneliness can effect on disease outcome [2].

A specific type of cancer, Ovarian Cancer, has been chosen for this review, especially for the psychological aspect. Main motivations of this choice are: the nature of this aggressive illness associated with very poor survival and high recurrence rates. It is the most fatal malignancy of the female genital tract and the fourth most common cause of female cancer death. This is because it is frequently detected at advanced stage, with a 5 -year survival rate of $46 \%$ for all the stages and $31 \%$ for advanced stages [3]. The management of ovarian cancer that normally includes radical pelvic surgery and multiple aggressive courses of chemotherapy, worsen the impact of this illness on patients' Quality of Life (QoL).

Ovarian Cancer patients and survivors tend to develop psychological disorders, as anxiety, depression and post-traumatic stress disorder [3-7]. There is also evidence of occurrence of constant impairments in social, familial, vocational, physical and sexual functioning, not confined to diagnosis and treatment but present in short and long-term cancer survivors [3].

General aim of this review is to analyze literature contributes examining the influence of typical activation patterns of the Autonomic Nervous System (ANS) in cancer and of specific psychological adaptive mechanisms on gynecological cancer. In particular, there are 4 specific aims:Identifying PNI pathways shown in literature as exacerbating factors in cancer; Identifying PNI pathways shown in literature as promoting cancer survivorship; Tracing in literature psychological variables shown as adaptive and linked to Quality of Life in patients with Cancer/Ovarian cancer; Tracing in literature specific areas of psychological pain in patients with Cancer/Ovarian cancer.

Correspondence to: Chiara Cosentino, Department of Clinical and Experimental Medicine, University of Parma, Via Gramsci,14, 43126 Parma, Italy, Tel: +39 347/2572416; E-mail: chiara.cosentino87@gmail.com

Key words: gynecological cancer, psychoneuroimmunology, heart rate variability, psycho-oncology, quality of life

Received: February 14, 2015; Accepted: March 06, 2015; Published: March 09, 2015 
A systematic review was made to address the aims listed above. Inclusion criteria: Were included scientific books and articles published between 2003-2013, on scientific journals; in English. Inclusion criteria were also the availability of full-text in English. Exclusion criteria: Were selected but are not discussed in this review articles relating to psychological aspects conducted in non-west culture countries. Were also selected in first instance articles about Cancer- related Fatigue, but weren't afterwards discussed because Cancer-related fatigue is intended as a iatrogenic symptom due to chemotherapy and radiotherapy.

\section{From macroenvironment to microenvironment}

Cancer recent research pointed out some new evidences on cancer biological dynamics, identifying the importance in its origin and metastatic pathway of the so-called "tumor microenvironment", the set of heterogeneous non cancer cells involved during the course of multistep tumorigenesis (Cancer Stem Cells, Immune Inflammatory Cells, Cancer Associated Fibroblast, Endothelial Cells, Pericyte) as in Hanahan \& Weinberg, 2011. The "Hallmarks of Cancer" have been identified including sustaining proliferative signaling, evading growth suppressors, resisting cell death, enabling replicative immortality, inducing angiogenesis, and activating invasion and metastasis. These hallmarks seem to be fostered by inflammation and by its components as cytokine, chemokine, macrophages and leucocytes [8-12].

Research also focused on the "Macroenviroment", meant as life context of the cancer patient. Evidences have been collected of the causal role stressful life eventand depression should have on higher mortality rate in patient with cancer different for site and type [13-15].

Thus becomes evident the presence of a model of impact of psychosocial stressors able to modulate tumor microenvironment, and through this, cancer progression [2]. The downstream activation of the Sympathetic Nervous System (SNS) and the hypothalamic-pituitaryadrenal axis (HPA) could exert selective physiologic pressures that initiate molecular signaling pathways involved in cancer hallmarks [16-18].

In order to achieve ultimate evidences of this influence "Macroenvironment-Microenvironment", experimental trials were conducted on animal models (mice and rats) of human cancer (ovarian, skin, colon), making it possible to artificially increase chronic stress. Thus researchers highlighted the effects of stress on tumor growth and, enriching the environment, showed its link to decreased cells proliferation and decreased tumor growth [19-21].

\section{Glucocorticoids (GCs)}

A chronic and unrelenting stress, with an insufficient perceived social support, can deregulate functioning glucocorticoids pathway [22].

In clinical trial "in vivo" on different solid tumor cells (brain, breast, colon, ovary and others) has been observed that pharmacological GCs hormone (i.e. Cortisone) administration could stimulate antiapoptotic gene expression and antagonize the ability of cancer cytotoxic treatments to induce cell death [23].

An experiment conducted on rats genetically prone to mammary tumor formation, the social environment influence on cancer progression and malignancy was examined. Isolated animals did develop significant dysregulation of cortisol responses to everyday stressors. Corticosterone response to an acute stressor was enhanced and recovery was markedly delayed, associated with increased mammary tumor progression [24].

Flattened cortisol circadian levels in metastatic breast patients, might be related to tumor burden and linked to specific psychological conditions [22]. In presurgical breast cancer patients, distress and avoidant coping were related to flattened diurnal cortisol rhythms; given that circadian cycles regulate tumor growth, this could highlight possible psychosocial effects in cancer-related circadian disruption [25].

GCs effect on tumor progression also through the microenvironment, affecting tumor-stroma cells, with a notable role in tumor invasion and migration [26,27]. GCs also influence tumor progression deregulating immune system and systemic metabolism $[28,29]$.

\section{Catecholamine}

Epinephrine (E), Norepinephrine (NE) and Dopamine (DA) affect almost each phase of the metastatic cascade. Angiogenesis: In a model of orthotopicallyxenografted human ovarian tumors in nude mice, a tumor growth-promoting effect was observed in animals following exposure to chronic stress; this increase in tumor growth was associated with the up-regulation of VEGF, a pro-angiogenic cytokine, in tumor tissues. In vitro studies also demonstrated the NE-mediated secretion of VEGF by ovarian carcinoma cells. In addition, studies have also indicated that NE induces a significant increase in the synthesis and release of other pro-angiogenic factors, including IL-6, other important cytokine [30]. Invasion: in vitro cell migration studies showed that $\mathrm{NE}$ is a potent inducer of migratory activity in carcinoma cell lines of colon, prostate, ovarian cancer cells and breast tissue origin, and this finding has been confirmed in a mouse model. That cell migration is mediated by adrenergic receptors and the the beta-blocker adrenergic receptor antagonist drug inhibits the process [31]. Anoikis: in animal model of prostate cancer, E activate an antiapoptotic signaling pathway [32]. However, DA can induce apoptosis, as shown in in vivo and in vitro ovarian cancer cells [33]. Immunity: Catecholamine could effect on the immune system, reducing typel cytokine, $\mathrm{T}$ cells and natural killer cell activity, enabling tumor cells to avoid elimination [33].

\section{Inflammation}

Pro-inflammatory cytokines, as IL-6 secreted after a stressful interaction, play a key role in cancer progression and could be a prognostic indicator of survival and metastasis [34].

A trial on animal model of human cancer (colon and mammary) showed that a functional impairment in immune system related to myeloid-derived suppressor cells (MDSC) inhibits immune cell responsiveness to anti-viral/tumor interferon, that directly inhibits tumor growth and coordinates anti-tumor innate and adaptive immunity [35]. In a randomized clinical trial on patients with breast cancer, individual with higher level of psychosocial stress, showed significant alterations of MDSC and higher levels of circulating IL6, with an evidence of higher cancer recurrence than control [36]. Moreover, IL-6 seems to effect on Central Nervous System (CNS); in patients with epithelial ovarian cancer, higher level of IL-6 produced in ovarian carcinoma microenvironments, elicited sickness behaviors in the CNS, contributing to depressive symptomatology, thus creating a negative feedback loop [37].

\section{Balance in a breath}

The Heart Rate Variability (HRV) consists of the changes in the time intervals between consecutive heartbeats (Task Force of the European Society of Cardiology and the North American Society of Pacing and Electrophysiology, 1996). HRV can serve as signal markers for various physiological or pathological events such as unplanned remission for geriatric patients, infections in critically ill patients and risk of myocardial infarction [38-40]. 
HRV is modulated by multiple regulatory mechanisms that operate on different time scales; the 24-hours HRV recording is produced by the interaction of circadian rhythms, core body temperature and metabolism. The short-term measurement (i.e. 5 minutes) recording is instead produced by autonomic, cardiovascular and respiratory system, thus becoming a valid marker of parasympathetic cardiac vagal control and reflecting the status of the autonomic nervous system [41].

In healthy conditions, there is a dynamic balance between SNS and PNS on Heart Rate [41]. Specifically, PNS influence is predominant at rest, its activation, in fact, can slow down HR of 20-30bpm, and even briefly interrupt it [41]. The influence of PNS on HRV implements through the Vagus Nerve, which allows the physiological mechanism of Respiratory Sinus Arrhythmia (RSA). The HR oscillations change in correspondence of breathing; in particular they should be systematically increased during relaxed states and decreased in stress phases [42].

The role of the Vagus Nerve on heart regulation has been recently analyzed in a new perspective, thanks to the Polyvagal Theory proposed by Stephen W. Porges.

The Polyvagal Theory emphasizes the neurophysiological and neuroanatomical distinction between two branches of the Vagus Nerve and proposes that each branch supports different adaptive behavioral strategies [43]. The systems identified, which through specific physiologic pathways modulate different behaviors, are the Social Engagement System (SES), the Mobilization System and the Immobilization System.

In this perspective, the SES plays a key role, consisting of a somatomotor component, which involves visceral efferent pathways that regulate the striated muscles of the face and head and a visceromotor component, involving the Myelinated Vagus that regulates the heart and bronchi [44]. This role was defined as "vagal brake", in which rapid inhibition and disinhibition of vagal tone to the heart can rapidly mobilize or calm an individual. Functionally, the vagal brake, by modulating visceral state, enables the individual to rapidly engage and disengage with objects and other individuals and to promote self-soothing behaviors and calm states, allowing hypothesizing the existence of a Cardiac Vagal Tone (CVT) [43]. Thus, a physiological state characterized by increased vagal influence on the heart would support spontaneous social engagement behaviors also through functional and structural links between neural control of the striated muscles of the face and the smooth muscles of the viscera [44].

\section{HRV and pathology: Influences and intervention}

Literature has shown that a meager HRV can be seen as a predictor of generic and specific mortality [45]. On the other hand, there is evidence that healthy longevity depends on preservation of autonomic function, in particular, HRV-parasympathetic function [46].

The relation of HRV and specific pathologies, has been shown in chronic illnesses, in which a higher vagal tone, registered through HRV, controls the activation of the anti-inflammatory reflex, acetylcholine mediated [47].

In the specific field of cancer, some evidence of the influence of PNS activity on cancer prognosis has been reached. In male patients with locally recurrent or metastatic cancer (principally lung and gastrointestinal cancer) a higher HRV is significantly associated to survival; in patients with different cancer sites, HRV appears systematically decreased; in patients with terminal hepatocellular carcinoma, HRV indices were significantly associated with Time-toDeath [48-50]. This influence can be understood since Vagal afferents and efferents might inhibit three mechanisms involved in cancer etiology and progression: local oxidative stress and DNA damage, inflammatory reactions and excessive sympathetic responses [51].

Moreover, in patients with colorectal cancer, high HRV predicts lower levels of tumor markers, one year later diagnosis, independently of confounders like treatment and cancer stage [52]. HRV multiple measures have also been integrated into a unique measure for the tracking of sepsis development in patients who underwent bone marrow transplant for hematological malignancy [53].

Surprisingly, there is a lack of studies directly referring to HRV in ovarian cancer.

Literature shows that is possible to deal with HRV, thus enhancing PNS activity. Physical activity has proved to be a good instrument to improve HRV; daily exercise alters ANS, thus reducing inflammation in many chronic illnesses and a moderate aerobic endurance activity seems to improve autonomic cardiac regulation and consequently quality of life (QoL) in cancer patients both during and after acute cancer treatment [45].

Other interventions have been examined in literature; in a randomized trial on healthy subjects, HRV biofeedback through abdominal breathing induced a short-term carry-over effect during both the rest period and laboratory induced stress [54]. Also the Eurythmy Therapy, an anthroposophic movement therapy aimed at reducing fatigue symptoms and stress levels, led to significant improvements in HRV as well as Mindfulness Meditation Program and Mind-Body Bridging Program , interventions based on body awareness and meditation skills, which have proved to be effective on SNS tone reduction in patients with cancer different types $[55,56]$.

\section{Creating well-being}

Surviving cancer does not just mean recovering one's physical health and adding theoretical years back to one's life expectancy; it also means coping with emotional, social, occupational, financial issues that accompany the acute, and sometimes chronic, experience of cancer. Dealing with this, in order to restore subjective well-being has been defined hygiology, "locating and developing personal and social resources and adaptive tendencies" (Super, 1955) even in the midst of distressing or abnormal life conditions. According to hygiology, health can be defined in relative terms; different individuals faced with cancer may differ markedly in their psychological adaptation based, in part, on the strengths, resources, and coping methods. Rather than focusing only on ameliorating psychological symptoms (anxiety, depression), a hygiological response would be more concerned with how to support individuals' positive coping tendencies and resources [57].

\section{Psychological symptomatology}

Not many specific researches have focused on Ovarian Cancer psychological symptoms; in Stafford et al. study, was investigated a sample of Gynecological Cancer survivors, including Ovarian, who reported no differences than breast cancer [58,59]. A specific longitudinal investigation of psychological morbidity in patients with Ovarian Cancer showed that most of the women were "occasional" cases of anxiety (52\%) and a subset of patients was stable cases of anxiety (22\%), especially in younger women [6].

\section{Coping and quality of life}

Coping strategies can be problem-focused, aimed to resolve the stressor, emotion-focused, aimed at managing internal aspects of the stressor and, in cancer, meaning-making, the recovery of meaning or making new meaning when facing highly stressful situations [60]. Strategies employed by individuals with cancer are fundamental in 
increasing or decreasing psychological distress, directly affecting patients QoL. For individuals living with an illness such as advanced cancer, acceptance coping strategies means to invest in a renewed sense of self. As a coping strategy frequently used by individuals with advanced cancer in order to accept their condition, studies detected spirituality and religion [61,62]. This strategy correlates with an improve in QoLand to the attribution of meaning to illness condition [63]. In Ovarian Cancer, QoL is one of the most relevant outcomes mostly because advances in medicine developed new treatments, but these have associated side-effects and toxicities that may impact on women QoL. In a longitudinal study has been demonstrated that an improvement in QoL, here observed as for global function, appetite loss and constipation, during the first 3 months of treatment is significantly associated with improved survival time [64]. In women with recurrent ovarian cancer, progressive deterioration in QoL could be an indicator of death within six months and coping strategies based on acceptance could ameliorate perceived QoL [65]. QoL seems to be directly affected by surgical treatment (frequently leading to hysterectomy of oophorectomy), organic factors treatment related (pain, nausea, fatigue), psychological distress (anxiety, anger, guilt and depression) and sexual dysfunctions [66-68]. Other risk factors for QoL deterioration in these patients are prolonged and multimodal treatments, young age and disengaged coping strategies [69].

\section{Self- advocacy}

Self-advocacy (SA), has been defined as an assertiveness an willingness to represent one's own interest when managing a life threatening disease; this construct first originated in researches on HIV/ AIDS and mental disabilities populations [70]. In cancer survivorship, SA has been defined as an important and modifiable skill able to impact on patients' health outcomes and QoL [71]. In a pioneering qualitative study conducted through focus groups in ovarian cancer, emerged that SA seems a fundamental component in illness adjustment; for these women $\mathrm{SA}$ is a process for recognizing and meeting their needs, learning one's needs and priorities as a cancer survivor and negotiating with healthcare teams, social supports, and other survivors to meet these needs [72]. These findings may recall Ferrell et al. ethnographic research, in which 1282 communications from women with ovarian cancer were collected and analyzed. Main theme that emerged referring to survival skills, and that can remind of SA construct, were: sense of control, anxiety and depression (acceptance), focus on living, appreciation of life, supporting other survivors, optimism, balance, accessing all possible treatments, persistence, expressing emotions, humor and normalcy [73].

\section{Support, intimacy and sexuality}

The perceived support, related to friends and to intimate relationship, seems to play a key role in cancer adaptation and survival. In women with breast cancer a perceived lack of friendship, marital and familial support correlates with higher distress and more difficulties in illness acceptance and management [74]. Evidences have been collected that a lack of support reciprocity with one's partner often exacerbates coping difficulties in the context of a range of life-threatening illnesses; the nature of these unsupportive interactions involves avoidance of the patient or criticism of her coping efforts [75]. In women with ovarian cancer, the role of support should be deeply inflect in its aspect linked to intimacy and sexuality. In some studies emerged that social support could play a protective role with respect to IL-6 elevations, distress and depressive symptoms, with a consequent strong impact on QoL $[28,37]$. In these women, changes in sexuality can directly affect couple relationship [76]. In addition, treatment-related infertility or the possibility of infertility on young women has a negative impact on couple and intimacy [77]. Analyzing the aspect of sexuality, there is evidence that ovarian cancer has a negative impact on each of the four stages of feminine sexual response. Surgical treatments on parts of body linked to womanhood and femininity alter body image, with physical and emotional trauma and this led to the labeling of these treatments as "invisibles femininity assaults" [78]. Thus in these women can be detected disabling problems with diminished sexual functioning, body image, and sudden identity changes due to the loss of physical integrity, leading to distancing in intimate relationships $[79,80]$. These patients frequently manifest distress, feeling of loss and do not feel a woman anymore $[81,82]$. This has a strong impact on sexual self-schema, cognitive generalizations about sexual aspects of oneself which are manifest in current experience, guide sexual behavior and influence the processing of sexually-relevant information [83]. Thus becomes evident that the type and radicalism of surgical treatment for Ovarian Cancer can influence sexual function and play a significant role in QoL [84].

In conclusion, current literature till now collected seems to allow hypothesizing a complex model of direct influence of specific psychological factors on cancer survivorship that can be defined "Integrated Model of Defense" (Figure 1).

It seems possible to focus on psychoneuroimmunological mechanisms not looking anymore on cancer progression and metastasis, but on the protective role that physiological activity (HRV) through anatomical and functional specific systems (Myelinated Vagus) could have in cancer survivorship. The enhancement of this activity could be reached through external, "mechanical" interventions (physical activity, biofeedback). Neverthless, referring to Porges' Polyvagal Theory, it seems possible to operate on the psychological conditions of cancer patients, in particular on social support, here meant as the possibility to recognize and emotionally share the burden of a chronic and life-threatening disease as cancer. Conversely, frequently this illness goes with a withdrawal from intimate relationship, because of feelings of fear and shame patients can feel about their conditions. This can be particularly true for Ovarian Cancer, where there is a strong component linked to sexual functioning and the body image that leads to a dramatic social retirement. View the lack of study addressing HRV

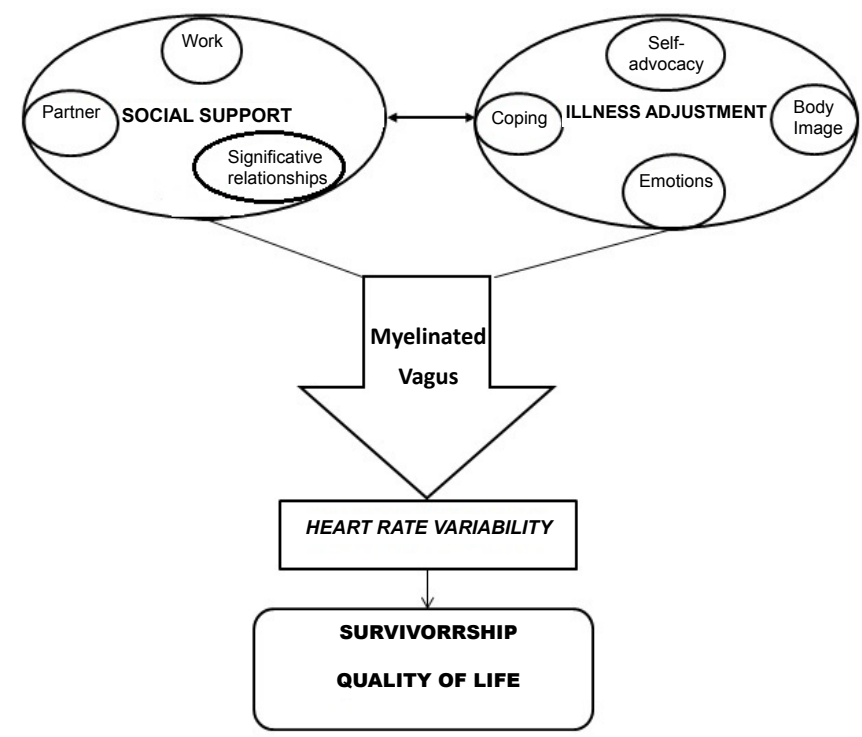

Figure 1. Integrated Model of Defense (IMD), proposed by Cosentino \& Pruneti. 
Cosentino C (2015) Towards an integrated model of defense in gynecological cancer. Psychoneuroimmunological and psychological factors, between risk and protection in cancer: A review

in Ovarian Cancer, it seems reasonable to wish for new researches in order to verify if in this sample, characterized by gender singularity and by specific psychological and physical impairments, is possible to apply this "Integrated Model of Defense" (IMD) in which perceived and effective support, illness adjustment and physiological indexes can effectively increase time and quality of survivorship.

\section{References}

1. Karelina K, DeVries AC (2011) Modeling social influences on human health. Psychosom Med 73: 67-74. [Crossref]

2. Green McDonald P, O'Connell M, Lutgendorf SK (2013) Psychoneuroimmunology and cancer: a decade of discovery, paradigm shifts, and methodological innovations. Brain Behav Immun 30 Suppl: S1-9. [Crossref]

3. Gonçalves V, Jayson G, Tarrier N (2011) A longitudinal investigation of posttraumatic stress disorder in patients with ovarian cancer. J Psychosom Res 70: 422-431. [Crossref]

4. Hipkins J, Whitworth M, Tarrier N, Jayson G (2004) Social support, anxiety and depression after chemotherapy for ovarian cancer: a prospective study. $\mathrm{Br} J$ Health Psychol 9: 569-581. [Crossref]

5. Norton TR, Manne SL, Rubin S, Carlson J, Hernandez E, et al. (2004) Prevalence and predictors of psychological distress among women with ovarian cancer. J Clin Oncol 22: 919-926. [Crossref]

6. Gonçalves V, Jayson G, Tarrier N (2008) A longitudinal investigation of psychological morbidity in patients with ovarian cancer. Br J Cancer 99: 1794-1801. [Crossref]

7. Gonçalves V (2013) Quality of Life in Ovarian Cancer Treatment and Survivorship. Ovarian Cancer - A Clinical and Translational Update.

8. Gonda TA, Tu S, Wang TC (2009) Chronic inflammation, the tumor microenvironment and carcinogenesis. Cell Cycle 8: 2005-2013. [Crossref]

9. Solinas G, Germano G, Mantovani A, Allavena P (2009) Tumor-associated macrophages (TAM) as major players of the cancer-related inflammation. J Leukoc Biol 86: 1065-1073. [Crossref]

10. Hanahan D, Weinberg RA (2011) Hallmarks of cancer: the next generation. Cell 144 646-74. [Crossref]

11. Medrek C, Pontén F, Jirström K, Leandersson K (2012) The presence of tumor associated macrophages in tumor stroma as a prognostic marker for breast cancer patients. BMC Cancer 12: 306. [Crossref]

12. Pitroda SP, Zhou T, Sweis RF, Filippo M, Labay E, et al. (2012) Tumor endothelial inflammation predicts clinical outcome in diverse human cancers. PLoS One 7: e46104. [Crossref]

13. Chida Y, Hamer M, Wardle J, Steptoe A (2008) Do stress-related psychosocial factors contribute to cancer incidence and survival? Nat Rev Clin Oncol 5: 466-475. [Crossref]

14. Satin JR, Linden W, Phillips MJ (2009) Depression as a predictor of disease progression and mortality in cancer patients: a meta-analysis. Cancer 115: 5349-5361. [Crossref]

15. Pinquart M, Duberstein PR (2010) Depression and cancer mortality: a meta-analysis. Psychol Med 40: 1797-1810. [Crossref]

16. Cole SW, Sood AK (2012) Molecular pathways: beta-adrenergic signaling in cancer. Clin Cancer Res 18: 1201-1206. [Crossref]

17. Hara MR, Kovacs JJ, Whalen EJ, Rajagopal S, Strachan RT, et al. (2011) A stress response pathway regulates DNA damage through $\beta 2$-adrenoreceptors and $\beta$-arrestin-1. Nature 477: 349-353. [Crossref]

18. Lutgendorf SK, Sood AK (2011) Biobehavioral factors and cancer progression: physiological pathways and mechanisms. Psychosom Med 73: 724-730. [Crossref]

19. Thaker PH, Han LY, Kamat AA, Arevalo JM, Takahashi R, et al. (2006) Chronic stress promotes tumor growth and angiogenesis in a mouse model of ovarian carcinoma. Nat Med 12: 939-944. [Crossref]

20. Sood AK, Armaiz-Pena GN, Halder J, Nick AM, Stone RL, et al. (2010) Adrenergic modulation of focal adhesion kinase protects human ovarian cancer cells from anoikis. J Clin Invest 120: 1515-1523. [Crossref]

21. Cao L, Liu X, Lin EJ, Wang C, Choi EY, et al. (2010) Environmental and genetic activation of a brain-adipocyte BDNF/leptin axis causes cancer remission and inhibition. Cell 142: 52-64. [Crossref]

22. Volden PA, Conzen SD (2013) The influence of glucocorticoid signaling on tumor progression. Brain Behav Immun 30 Suppl: S26-31. [Crossref]
23. Zhang C, Wenger T, Mattern J, Ilea S, Frey C, et al. (2007) Clinical and mechanistic aspects of glucocorticoid-induced chemotherapy resistance in the majority of solid tumors. Cancer Biol Ther 6: 278-287. [Crossref]

24. Hermes GL, Delgado B, Tretiakova M, Cavigelli SA, Krausz T, et al. (2009) Social isolation dysregulates endocrine and behavioral stress while increasing malignant burden of spontaneous mammary tumors. Proc Natl Acad Sci U S A 106: 22393-22398. [Crossref]

25. Dedert E, Lush E, Chagpar A, Dhabhar FS, Segerstrom SC, et al. (2012) Stress, coping, and circadian disruption among women awaiting breast cancer surgery. Annals of Behavioral Medicine 44: 10-20. [doi:10.1007/s12160-012-9352-y]

26. Smith RA, Lea RA, Weinstein SR, Griffiths LR (2007) Progesterone, glucocorticoid, but not estrogen receptor mRNA is altered in breast cancer stroma. Cancer Lett 255: 77-84. [Crossref]

27. Hidalgo AA1, Montecinos VP, Paredes R, Godoy AS, McNerney EM, et al. (2011) Biochemical characterization of nuclear receptors for vitamin D3 and glucocorticoids in prostate stroma cell microenvironment. Biochem Biophys Res Commun 412: 13-19. [Crossref]

28. Costanzo ES, Lutgendorf SK, Sood AK, Anderson B, Sorosky J, et al. (2005) Psychosocial factors and interleukin-6 among women with advanced ovarian cancer. Cancer 104: 305-313. [Crossref]

29. Kaidar-Person O, Bar-Sela G, Person B (2011) The two major epidemics of the twentyfirst century: obesity and cancer. Obes Surg 21: 1792-1797. [Crossref]

30. Basu S, Dasgupta PS (2013) Catecholamine Neurotransmitters: An Angiogenic Switch in the Tumor Microenvironment. Angiogenesis Modulations in Health and Disease 77-86. [doi: 10.1007/978-94-007-6467-5]

31. Powe DG, Voss MJ, Zänker, KS, Habashy HO, Green R, et al. (2010) Beta-Blocker Drug Therapy Reduces Secondary Cancer Formation in Breast Cancer and Improves Cancer Specific Survival. Oncotarget 1: 628-638. [Crossref]

32. Hassan S, Karpova Y, Baiz D, Yancey D, Pullikuth A, et al. (2013) Behavioral stress accelerates prostate cancer development in mice. J Clin Invest 124: 874-886. [Crossref]

33. Armaiz-Pena GN, Cole SW, Lutgendorf SK, Sood AK (2013) Neuroendocrine influences on cancer progression. Brain Behav Immun 30 Suppl: S19-25. [Crossref]

34. Powell ND, Tarr AJ, Sheridan JF (2013) Psychosocial stress and inflammation in cancer. Brain Behav Immun 30 Suppl: S41-47. [Crossref]

35. Mundy-Bosse BL, Lesinski GB, Jaime-Ramirez AC, Benninger K, Khan M, et al (2011) Myeloid-derived suppressor cell inhibition of the IFN response in tumor-bearing mice. Cancer Res 71: 5101-5110. [Crossref]

36. Mundy-Bosse BL, Thornton LM, Yang HC, Andersen BL, Carson WE (2011) Psychological stress is associated with altered levels of myeloid-derived suppressor cells in breast cancer patients. Cell Immunol 270: 80-87. [Crossref]

37. Lutgendorf SK, Weinrib AZ, Penedo F, Russell D, DeGeest K, et al. (2008) Interleukin-6, cortisol, and depressive symptoms in ovarian cancer patients. $J$ Clin Oncol 26: 4820-4827. [Crossref]

38. Chiang JK, Koo M, Kuo TB, Fu CH (2010) Association between cardiovascular autonomic functions and time to death in patients with terminal hepatocellular carcinoma. J Pain Symptom Manage 39: 673-679. [Crossref]

39. Ahmad S, Tejuja A, Newman KD, Zarychanski R, Seely AJ (2009) Clinical review: a review and analysis of heart rate variability and the diagnosis and prognosis of infection. Crit Care 13: 232. [Crossref]

40. Buccelletti E, Gilardi E, Scaini E, Galiuto L, Persiani R, et al. (2009) Heart rate variability and myocardial infarction: systematic literature review and metanalysis. Eur Rev Med Pharmacol Sci 13: 299-307. [Crossref]

41. Tortora GJ, Derrickson BH (2012) Principles of anatomy and physiology $\left(13^{\text {th }}\right.$ edn $)$ New York: John Wiley \& Sons, Inc.

42. Lehrer P (2013) How Does Heart Rate Variability Biofeedback Work? Resonance, the Baroreflex, and Other Mechanisms. Biofeedback: Spring 41: 26-31.

43. Porges SW (2007) The polyvagal perspective. Biol Psychol 74: 116-143. [Crossref]

44. Porges SW (2009) The polyvagal theory: new insights into adaptive reactions of the autonomic nervous system. Cleve Clin J Med 76 Suppl 2: S86-90. [Crossref]

45. Niederer D, Vogt L, Thiel C, Schmidt K, Bernhörster M, et al. (2013) Exercise effects on HRV in cancer patients. Int J Sports Med 34: 68-73. [Crossref] 
Cosentino C (2015) Towards an integrated model of defense in gynecological cancer. Psychoneuroimmunological and psychological factors, between risk and protection in cancer: A review

46. Zulfiqar U, Jurivich DA, Gao W, Singer DH (2010) Relation of high heart rate variability to healthy longevity. Am J Cardiol 105: 1181-1185. [Crossref]

47. Eftekhari G, Ahmadi Soleimani SM, Mani AR (2013) Heart rate variability, vagal activity and the pulse of inflammation. J Intern Med 274: 490-491. [Crossref]

48. Fadul N, Strasser F, Palmer JL, Yusuf SW, Guo Y, et al. (2010) The association between autonomic dysfunction and survival in male patients with advanced cancer: a preliminary report. J Pain Symptom Manage 39: 283-290. [Crossref]

49. Kim do H, Kim JA, Choi YS, Kim SH, Lee JY, et al. (2010) Heart rate variability and length of survival in hospice cancer patients. J Korean Med Sci 25: 1140-1145. [Crossref]

50. Chiang JK, Fu CH, Kuo TB, Koo M (2011) Association between frequency domain heart rate variability and unplanned readmission to hospital in geriatric patients. $B M C$ Public Health 11: 137. [Crossref]

51. De Couck M, Mravec B, Gidron Y (2012) You may need the vagus nerve to understand pathophysiology and to treat diseases. Clin Sci (Lond) 122: 323-328. [Crossref]

52. Mouton C, Ronson A, Razavi D, Delhaye F, Kupper N, et al. (2012) The relationship between heart rate variability and time-course of carcinoembryonic antigen in colorectal cancer. Auton Neurosci 166: 96-99. [Crossref]

53. Bravi A, Green G, Longtin A, Seely AJ (2012) Monitoring and identification of sepsis development through a composite measure of heart rate variability. PLoS One 7: e45666. [Crossref]

54. Lujan HL, DiCarlo SE (2013) Physical activity, by enhancing parasympathetic tone and activating the cholinergic anti-inflammatory pathway, is a therapeutic strategy to restrain chronic inflammation and prevent many chronic diseases. Med Hypotheses 80: 548-552. [Crossref]

55. Prinsloo GE, Derman WE, Lambert MI, Laurie Rauch HG (2013) The effect of a single session of short duration biofeedback-induced deep breathing on measures of heart rate variability during laboratory-induced cognitive stress: a pilot study. Appl Psychophysiol Biofeedback 38: 81-90. [Crossref]

56. Seifert G, Kanitz JL, Pretzer K, Henze G, Witt K, et al. (2013) Improvement of circadian rhythm of heart rate variability by eurythmy therapy training. Evid Based Complement Alternat Med 2013: 564340. [Crossref]

57. Lipschitz DL, Kuhn R, Kinney AY, Donaldson GW, Nakamura Y (2013) Reduction in salivary $\alpha$-amylase levels following a mind-body intervention in cancer survivors--an exploratory study. Psychoneuroendocrinology 38: 1521-1531. [Crossref]

58. Stafford L, Judd F, Gibson P, Komiti A, Mann GB, Quinn M (2013) Screening for depression and anxiety in women with breast and gynaecologic cancer: course and prevalence of morbidity over 12 months. Psychooncology 22: 2071-2078. [Crossref]

59. Lent RW (2007) Restoring Emotional Well-Being. A Theoretical Model 13: 231-247.

60. Park CL (2010) Making sense of the meaning literature: an integrative review of meaning making and its effects on adjustment to stressful life events. Psycholo Bull 136: 257-301. [Crossref]

61. Alcorn SR, Balboni MJ, Prigerson HG, Reynolds A, Phelps AC, et al. (2010) "If God wanted me yesterday, I wouldn't be here today": religious and spiritual themes in patients' experiences of advanced cancer. J Palliat Med 13: 581-588. [Crossref]

62. Balboni TA, Vanderwerker LC, Block SD, Paulk ME, Lathan CS, et al. (2007) Religiousness and spiritual support among advanced cancer patients and associations with end-of-life treatment preferences and quality of life. J Clin Oncol 25: 555-560. [Crossref]

63. Carlson LE, Halifax J (2011) Mindfulness for cancer and terminal illness. In L. M. McCracken (Edn), Mindfulness and acceptance in behavioral medicine: 159-186, California: New Harbinger.

64. Ciarrochi J, Fisher D, Lane L (2011) The link between value motives, value success, and well-being among people diagnosed with cancer. Psychooncology 20: 1184-1192. [Crossref]

65. Gupta D, Braun DP, Staren ED, Markman M (2013) Longitudinal health-related quality of life assessment: implications for prognosis in ovarian cancer. J Ovarian Res 6: 17. [Crossref]
66. Price MA1, Bell ML, Sommeijer DW, Friedlander M, Stockler MR, et al. (2013) Physical symptoms, coping styles and quality of life in recurrent ovarian cancer: a prospective population-based study over the last year of life. Gynecol Oncol 130: 162168. [Crossref]

67. Wenzel L, Vergote I, Cella D (2003) Quality of life in patients receiving treatmen for gynecologic malignancies: special considerations for patient care. Int J Gynaecol Obstet 83: 211-229. [Crossref]

68. Jonikas JA, Grey DD, Copeland ME, Razzano LA, Hamilton MM, et al. (2013) Improving propensity for patient self-advocacy through wellness recovery action planning: results of a randomized controlled trial. Community Ment Health J 49: 260 269. [Crossref]

69. Morris BA, Campbell M, Dwyer M, Dunn J, Chambers SK (2011) Survivor identity and post-traumatic growth after participating in challenge-based peer-support programmes. Br J Health Psychol 16: 660-674. [Crossref]

70. Brush LD (1999) Woman battering and welfare reform: The view from a welfare-towork program. J Soc \& Soc Welfare 26: 49.

71. Zebrack BJ, Landier W (2011) The perceived impact of cancer on quality of life for post-treatment survivors of childhood cancer. Qual Life Res 20: 1595-1608. [Crossref]

72. Hagan TL, Donovan HS (2013) Ovarian cancer survivors' experiences of selfadvocacy: a focus group study. Oncol Nurs Forum 40: 140-147. [Crossref]

73. Ferrell B, Smith SL, Cullinane CA, Melancon C (2003) Psychological well being and quality of life in ovarian cancer survivors. Cancer 98: 1061-1071. [Crossref]

74. Manne S, Ostroff J, Sherman M, Glassman M, Ross S, et al. (2003) Buffering effects of family and friend support on associations between partner unsupportive behaviors and coping among women with breast cancer. Journal of Social and Personal Relationships 20: 771-792.

75. Mallinckrodt B, Armer JM, Heppner PP (2012) A threshold model of social support, adjustment, and distress after breast cancer treatment. J Couns Psychol 59: 150-160. [Crossref]

76. Gilbert E, Ussher JM, Perz J (2011) Sexuality after gynaecological cancer: a review of the material, intrapsychic, and discursive aspects of treatment on women's sexualwellbeing. Maturitas 70: 42-57. [Crossref]

77. Penrose R, Beatty L, Mattiske J, Koczwara B (2013) The psychosocial impact of cancer-related infertility on women: a review and comparison. Clin J Oncol Nurs 17 188-193. [Crossref]

78. Butler L, Banfield V, Sveinson T, Allen K (1998) Conceptualizing sexual health in cancer care. West J Nurs Res 20: 683-705. [Crossref]

79. Juraskova I, Butow P, Robertson R, Sharpe L, McLeod C, et al. (2003) Post-treatmen sexual adjustment following cervical and endometrial cancer: a qualitative insight Psychooncology 12: 267-279. [Crossref]

80. Sacerdoti RC, Lagana' L, Koopman C (2010) Altered Sexuality and Body Image after Gynecological Cancer Treatment: How Can Psychologists Help? Prof Psychol Res Pr 41: 533-540. [Crossref]

81. Sekse RJ, Raaheim M, Blaaka G, Gjengedal E (2010) Life beyond cancer: women's experiences 5 years after treatment for gynaecological cancer. Scand J Caring Sci 24 799-807. [Crossref]

82. Stead ML, Fallowfield L, Selby P, Brown JM (2007) Psychosexual function and impact of gynaecological cancer. Best Pract Res Clin Obstet Gynaecol 21: 309-320. [Crossref]

83. Carpenter KM, Andersen BL, Fowler JM, Maxwell GL (2009) Sexual self schema a a moderator of sexual and psychological outcomes for gynecologic cancer survivors. Arch Sex Behav 38: 828-841. [Crossref]

84. Carter J, Stabile C, Gunn A, Sonoda Y (2013) The physical consequences of gynecologic cancer surgery and their impact on sexual, emotional, and quality of life issues. $J$ Sex Med 10: 21-34. [Crossref]

Copyright: (C) 2015 Cosentino C. This is an open-access article distributed under the terms of the Creative Commons Attribution License, which permits unrestricted use, distribution, and reproduction in any medium, provided the original author and source are credited. 